\title{
DOSSIÊ
}

\section{Estructura agraria y violencia rural en América Latina ${ }^{1}$}

CRISTÓBAL KAY*

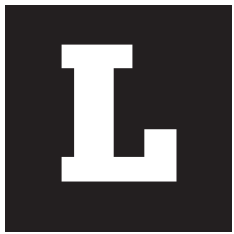

a violencia en las últimas décadas ha alcanzado niveles extraordinarios en América Latina. Por ejemplo, se calcula que a causa de la violencia unas 150,000 pesonas murieron en Guatemala (1968-1996), más de 75,000 en El Salvador (1979-1995), 44,000 en Colombia (1963-1998), 30,000 en Nicaragua (1982-1998) y 30,000 en Perú (1981-1995). Además millones de personas han sido desplazadas por la violencia. Una elevada proporción de las víctimas, en especial la población desplazada, proviene de las áreas rurales. Por ello, es importante analizar la sociedad rural a fin de entender los orígenes sociales de la violencia. Para tal propósito este ensayo estudia las relaciones entre estructura agraria, conflictos y violencia rural. Factores tales como el régimen político, los mercados, los cultivos (por ejemplo, la coca) y las acciones del Estado tienen una presencia importante en ese tipo de conflictos y violencia en el campo. Sin embargo, el grado de influencia de estos factores varía en buena medida según las características de la estructura agraria y las relaciones sociales existentes. Se examina en particular la influencia de las reformas agrarias y/o las demandas de los campesinos por una reforma agraria en la violencia rural

1 Una versión mucho más amplia de este ensayo fue publicada en la Revista Mexicana de Sociología, vol. 63, núm. 4, octubrediciembre, 2001, p. 159-195. 
tomando en consideración los casos de Chile, Perú, Colombia, Brasil, México y algunos países de América Central. En las conclusiones de este trabajo se presentan algunos discernimientos comparativos, si bien preliminares. Los estudios comparativos, en mi opinión, pueden aportar un marco analítico y contexto más amplio para un mejor entendimiento de las causas y consecuencias de la violencia rural.

En este ensayo argumento que la violencia rural en América Latina tiene sus raíces en un sistema agrario basado en la desigualdad y la exclusión, si bien su manifestación depende de una variedad de factores específicos tales como las circunstancias sociales y políticas. Así, para atacar el aspecto estructural de la violencia rural debe transformarse radicalmente el sistema agrario a fin de lograr mayor igualdad y participación democrática. Aunque la violencia rural tiene causas múltiples y diversas facetas, si no se hacen verdaderos esfuerzos por resolver a fondo el problema de la tierra no podrán solucionarse los conflictos rurales y la violencia. La violencia rural ha sido endémica y persistente a través de la historia de América Latina. La conquista y colonización de América Latina por los países ibéricos ha sido tal vez el episodio más dramático y violento de su historia. Se establecieron por la fuerza grandes latifundios en los cuales las comunidades campesinas perdieron sus tierras y muchas de ellas fueron sujetas a relaciones de servidumbre. Los enormes latifundios dominaban la economía y la sociedad agrarias desde el período colonial hasta las décadas de la reforma agraria generalmente de los 1960 a los 1980. La importancia del latifundio para entender los conflictos rurales y la violencia es tal que Eric Wolf (1973) distingue tres fases en la historia de los movimientos campesinos en América Latina, cada fase ligada a una etapa particular en el desarrollo del sistema de hacienda. Los conflictos, así como el tipo y grado de violencia, varían de una fase a otra. Es la tercera fase la que resulta de importancia particular para nuestro análisis. En ella las luchas campesinas, que cada día son más variadas, se centran principalmente alrededor de las demandas 
por la reforma agraria - expresadas en ocasiones por invasiones a latifundios -, por el derecho a formar sindicatos y por mejores salarios. A partir de la segunda guerra mundial, este tipo de protestas es cada vez más común. Las luchas y demandas campesinas por la reforma agraria son generalmente parte de un proceso más amplio de cambio político.

A raíz de la revolución cubana de 1959 los E.E.U.U., bajo la presidencia de John F. Kennedy, tomó la iniciativa de poner en marcha la Alianza para el Progreso con el ánimo de lograr la modernización en América Latina mediante reformas y evitar posibles revoluciones socialistas. Un aspecto importante de esta iniciativa era convencer a los gobiernos de América Latina a llevar a cabo programas de reforma agraria. Se aseguraba que la redistribución de la tierra y la proliferación de granjas familiares privadas convertiría un campesinado con potencial insurreccional en una fuerza social conservadora y estabilizadora para el campo. De hecho, diversos gobiernos de América Latina diseñaron programas de reforma agraria bajo la influencia de la Alianza para el Progreso. Muchas preguntas surgen en este sentido. ¿Tuvo éxito la reforma agraria al originar la incorporación social y política, o sea, superar la marginación tradicional de los campesinos del sistema político y social, y con ello reducir los conflictos y la violencia? O, por el contrario, ¿abrió la reforma agraria la caja de Pandora aumentando la inestabilidad política y social y la violencia? Estas preguntas se discutirán a continuación con referencia a los casos de Chile, Colombia, Brasil, México y América Central.

\section{La reforma agraria y contrarreforma en Chile}

El caso chileno ilustra una reforma agraria que se puso en marcha relativamente sin violencia a pesar de su carácter radical. Pero se trata también de una contrarreforma impuesto por un Estado autoritario mediante la violencia. Durante el período de la reforma agraria, que abarca de 
1964 a 1973, el número de muertes violentas no pasó de una docena. Cabe tomar en consideración que se expropió casi la mitad de las tierras de cultivo del país y muchos de los campesinos tomaron acción directa en un intento exitoso de acelerar el proceso de expropiación. Pero después del golpe militar de 1973, que derribó al gobierno socialista del presidente Allende, las muertes violentas se elevaron a varios miles en el campo. Campesinos activistas, dirigentes sindicales, beneficiarios de la reforma agraria e indígenas fueron las víctimas principales de la represión llevada a cabo en el campo por el Estado autoritario. Torturas, detenciones sin juicio, desapariciones, encarcelamientos por razones políticas y el terror generalizado se convirtieron en la norma. Era una guerra de clases en donde la represión tenía el claro propósito de destruir el movimiento campesino como parte de un objetivo más amplio del gobierno militar: exterminar cualquier posibilidad de que resurgiera un movimiento revolucionario.

El Estado desarticuló el movimiento campesino y los sindicatos campesinos - que fueron muy influyentes y hacia el final del gobierno de Allende llegaron a aglutinar a más de las dos terceras partes de los trabajadores agrícolas. Sin embargo, también la clase terrateniente tuvo que aceptar algunos cambios, entre ellos, que les fuera devuelta únicamente parte de sus propiedades y el resto se vendiera a nuevos grupos empresariales capitalista y a beneficiarios campesinos en parcelas -como eran conocidas estas nuevas granjas familiares surgidas de la subdivisión del sector reformado. La contrarreforma significó que cerca de la mitad de los campesinos beneficiarios de la reforma agraria quedaron sin tierra. Pero la parcelación llenaba una aspiración largamente sostenida por los campesinos de adquirir tierras en propiedad privada. Sin embargo, los parceleros representan una minoría del campesinado. Además cerca de la mitad de los parceleros tuvieron que vender su parcela en años posteriores porque no les fue posible enfrentar los pagos por sus tierras, o bien porque fueron arruinados por la política neoliberal. Pero el proceso de parcelización 
fue un factor importante para estabilizar el campo. Con la reforma agraria y la contrarreforma surgió una nueva estructura agraria en Chile. El latifundio había sido expropiado o transformado en granja capitalista moderna y ocupaba menos de la mitad de la tierra que había sido de su propiedad, mientras que el sector campesino había duplicado el área bajo su control. Si bien las políticas neoliberales introducidas por el gobierno militar condujeron a un nuevo proceso de concentración de las tierras, el sistema agrario es en la actualidad menos desigual y más flexible si se le compara con el período anterior a la reforma.

Los conflictos por la tierra y la violencia rural han disminuido en general desde 1990 con la transición a la democracia y es poco probable que resurjan movilizaciones como las del período de la reforma agraria. Pero en los últimos años grupos indígenas han invadido algunas granjas reclamando derechos de propiedad o ciertos derechos ancestrales, y exigen al gobierno la expropiación de tales granjas en su beneficio. A pesar del éxito de las exportaciones agrícolas en Chile, aún permanece el tema no resuelto de los indígenas que ha resultado en las movilizaciones rurales más importantes desde la caída del gobierno de Allende en 1973. El conflicto indígena surge a raíz de su falta de tierras y de su marginación de los beneficios del extraordinario crecimiento económico del país desde mediados de los años ochenta.

\section{La violencia en Perú antes y después de Sendero Luminoso}

Los conflictos en el campo y las demandas de los campesinos por la reforma agraria se intensificaron en Perú al inicio de los años sesenta. Uno de los movimientos campesinos más notables en ese momento estaba bajo el mando del líder troskista Hugo Blanco, activista importante en el valle de La Convención. Los arrendatarios se negaron a pagar alquiler a los terratenientes y exigían la expropiación de sus latifundios. Sin embargo, 
este movimiento se acalló unos años después cuando el gobierno de Belaúnde aceptó ampliamente sus demandas al expropiar varios latifundios y redistribuir la tierra entre sus antiguos arrendatarios como propiedad privada. No hay duda de que la reforma agraria de 1964 del presidente Belaúnde fue diseñada con propósitos políticos y se confinó únicamente a las áreas donde los conflictos rurales eran más intensos. Al repartir tierras entre los campesinos insurrectos, el gobierno deseaba comprar la paz social y tener mano libre para reprimir la incipiente lucha guerrillera. Tuvo éxito en ambos aspectos.

Entre tanto, la reforma agraria de 1969 del presidente Velasco Alvarado, después de un periodo inicial de relativa tranquilidad, condujo a la violencia ya que muchos campesinos se oponían a la dirección que había tomado la reforma agraria. Había resistencia contra el carácter estatista y colectivista de la reforma agraria pero, sobre todo, las comunidades de campesinos indígenas protestaron por su exclusión parcial, si no total, del reparto de tierras. Los campesinos de estas comunidades comenzaron a invadir las recién creadas granjas colectivas y estatales, exigiendo que parte de la tierra, si no toda, les fuera transferida. En algunos casos hubo violentos enfrentamientos entre los invasores y las fuerzas del orden que resultaron en muchos muertos y cientos de heridos. Esta insatisfacción de los comuneros fue la que Sendero Luminoso explotaría de manera tan despiadada y violenta. Perú es el ejemplo trágico de una política de reforma agraria que al tiempo en que resolvía algunos problemas, abrió el camino a nuevos resentimientos y conflictos, y dio origen así al surgimiento del movimiento violentista Sendero Luminoso. La reforma agraria, al destruir las relaciones de tipo feudal y el poder político y social de los terratenientes y gamonales, dejó un vacío de poder que ni el Estado, ni los partidos políticos y ni las organizaciones campesinas tuvieron la capacidad de llenar. Así la reforma agraria en Perú sembró sin proponérselo las semillas de la intensificación de la violencia.

En la guerra desencadenada por Sendero Luminoso, desde los años 
ochenta hasta comienzos de los años noventa, se estima que las víctimas fueron unas 25,000 personas y que además fueron desplazadas alrededor de 600,000 personas (Blum, 2001, p. 341-42) mientras que, por ejemplo, en la década anterior a Sendero las muertes por violencia socio-política no superaban varias centenas. Aunque el mal diseño de la reforma agraria contribuyó a tal violencia, otros factores contribuyeron a ella, tales como el arraigado racismo y la marginación de la población indígena en Perú. Son estos profundos resentimientos y frustraciones, en particular los de los comuneros ya descampesinados y desindianizados, lo que aprovechó Sendero en su violenta trayectoria. Sendero ofreció una nueva identidad y misión a los hijos e hijas de los comuneros quienes, gracias a las varias reformas del gobierno de Velasco Alvarado, habían mejorado su educación y, en algunos casos, tenían acceso a las universidades de provincia, aunque no habían podido conseguir un trabajo adecuado y, por lo mismo, veían frustrado su ascenso en la escala social. Estos jóvenes se convirtieron en un campo fértil de reclutamiento para Sendero, que los utilizó para penetrar en las comunidades indígenas y obtener su apoyo. Estudios han revelado que donde la reforma agraria distribuyó tierras entre comunidades campesinas durante el proceso inicial de expropiación o, con más frecuencia, después de que los comuneros habían invadido granjas del sector reformado, Sendero ya no tenía capacidad de hacer más incursiones. Además las comunidades y granjas del sector reformado bien organizadas y/o con vínculos cercanos con partidos políticos - en especial de la izquierda civil (no insurreccional) - pudieron resistir las incursiones de Sendero (Degregori, 1992). Si bien la reforma agraria en Perú tiene una responsabilidad importante por la violencia desencadenada, significó el parteaguas en la historia del país y un paso esencial, aunque insuficiente, para empezar a resolver el problema agrario e indígena. No obstante, Sendero jamás habría logrado tal importancia ni hubiera cobrado tantas vidas si la reforma agraria hubiera incorporado desde el inicio a las comuni- 
dades campesinas al proceso de redistribución de la tierra.

Un factor clave en la derrota de Sendero fue la existencia, formación y desarrollo de las rondas campesinas. Las rondas son una suerte de comités de vigilancia organizados por las propias comunidades. Ya existían en el norte de Perú antes del nacimiento de Sendero y se habían formado para prevenir el robo de ganado. Cuando el gobierno se dio cuenta de que no podía derrotar a Sendero con sus propios medios, promovió la formación de organizaciones parecidas a las rondas originales, los llamados Comités de Autodefensa Civil. El cambio de estrategia del gobierno y los militares hacia las rondas contribuyó también a la derrota de Sendero. En vez de considerar a las rondas como organizaciones potenciales de terroristas que simpatizaban con Sendero, el gobierno empezó a darse cuenta que se trataba de verdaderas asociaciones de base que intentaban defender la supervivencia de sus miembros y compensar las fallas del Estado en su incapacidad para protegerlos contra los robos y crímenes, administrar la justicia según su parecer y proporcionarles los servicios más esenciales. Así los militares comenzaron a establecer lazos con las rondas y a proveerlas de armas para defenderse de Sendero. En resumen, un factor importante en la derrota de Sendero Luminoso fueron las comunidades campesinas que habían sido también las principales víctimas de Sendero, así como las víctimas iniciales de las fuerzas de seguridad.

\section{La violencia constante en Colombia}

Colombia, con razón o sin ella, evoca en la mente de muchos la imagen de la violencia perpetua. De hecho, los mismos colombianos se refieren a uno de sus períodos históricos, el de los años cincuenta y sesenta, como la época de La Violencia. No podían prever, aunque tal vez lo temían, que los años ochenta y noventa se convertirían en una época aún más violenta. Los diversos aspectos de la violencia en Colombia y sus caracterís- 
ticas cambiantes a lo largo de la historia dificultan su análisis y comprensión. Se trata de un tejido complejo de factores en interacción, de múltiples facetas y elementos en evolución. Sus causas y manifestaciones son múltiples. Por tanto, no es sorprendente que las interpretaciones sobre la violencia en ese país difieran más marcadamente que en otros países de América Latina. El mismo Estado se ha involucrado en muchos actos ilegales de violencia, perpetrados por las fuerzas armadas, la policía y grupos paramilitares asociados con éste. La interrelación entre el problema de la tierra y la violencia es particularmente compleja. Pero a pesar de las diversas interpretaciones de las causas y consecuencias de la violencia, la mayoría de los autores están de acuerdo en que el problema de la tierra es uno de los principales factores para explicar la violenta historia del país.

En lo que sigue he adoptado la útil periodización de Meertens (1997) sobre la violencia en Colombia. El primer período, durante los años treinta, está caracterizado por un repunte de la violencia. En esos años, Colombia fue testigo del crecimiento de las organizaciones y acciones campesinas, en particular en las zonas cafetaleras, particularmente ricas. A través de sus organizaciones, los campesinos exigían la abolición de los servicios de trabajo opresivos y explotadores de tipo feudal que los arrendatarios debían pagar a los latifundistas. También llevaron a cabo campañas por el derecho de cultivar el café en sus propiedades y de adquirir derechos de propiedad. El gobierno, en su intento (fallido) por disminuir los conflictos - con frecuencia violentos - entre campesinos y terratenientes, promulgó en 1936 la Ley de Tierras. Dicha ley buscaba modernizar los latifundios tradicionales, proporcionar títulos de propiedad a los pequeños productores que aún no habían legalizado la ocupación de un pedazo de tierra (con frecuencia propiedad del Estado) cultivada por ellos durante muchos años; y efectuar el reparto de tierras a los colonos y arrendatarios mediante la expropiación de latifundios considerados ineficientes porque mantenían grandes superficies sin cultivar. Sin embargo, los latifundistas se defendieron de tal 
legislación expulsando, con frecuencia por medios violentos, a los colonos y pequeños arrendatarios.

El segundo período está caracterizado por La Violencia, del final de los años cuarenta a los sesenta, durante el cual se dio una dramática escalada de homicidios que afectaban el campo en particular. Entre 1946 y 1966 el número de muertos por violencia sobrepasó los 200,000, o sea 2.8\% de la población total de 15 años o más de edad (Oquist, 1980, p. 910). En el inicio de los años sesenta, Colombia tenía todavía la tasa de mortalidad por violencia más elevada del mundo. El gobierno, dominado por el Partido Conservador, desencadenó una ola de represión en contra del movimiento campesino por temor a que éste ganara fuerza. Algunas organizaciones campesinas, como consecuencia del terror de Estado, se convirtieron en movimientos guerrilleros, de modo que su objetivo ya no iba dirigido solamente a la clase terrateniente, sino también al gobierno conservador. El movimiento guerrillero fue cooptado por el Partido Liberal, el principal partido de oposición al gobierno, lo cual, a su vez, condujo al Partido Conservador a organizar sus propias bandas armadas. El conflicto se convirtió en una lucha entre los dos partidos políticos por el control del gobierno y del país. Así, La Violencia era una competencia política entre las élites por medios violentos, con frecuencia en el plano regional. Las demandas de los campesinos fueron ignoradas y el bandolerismo se hizo común. Este bandolerismo político era parte de una estrategia individual, tradición característica de los pequeños y medianos cafetaleros similar al de «formas cotidianas de resistencia campesina» analizado por James Scott. El movimiento campesino fue fracturado y desarticulado para convertirse en facciones donde los campesinos apoyaban a grupos armados, ya fueran conservadores o liberales.

El tercer período, en los años setenta, fue menos violento. El sistema agrario se volvió más complejo con el advenimiento del «capitalismo desde arriba», conforme algunos hacendados modernizaron sus latifundios. Esto 
se complementó con un «capitalismo desde abajo», es decir, el surgimiento de una nueva clase de capitalistas agrarios, quienes con anterioridad habían sido principalmente arrendatarios, colonos o pequeños productores, que pudieron comprar las tierras cultivadas por ellos y con el tiempo acumularon más. La organización campesina más importante en el país, la Asociación Nacional de Usuarios Campesinos (ANUC), perdió fuerza al final de ese período y dejó un vacío político que fue ocupado por la guerrilla y otros grupos armados, que aumentaban cada día en número, como los ligados con los narcotraficantes, los paramilitares y la milicia de autodefensa.

En el cuarto período, el de los años ochenta y noventa, la violencia dominó de nuevo la escena política. Los grupos de la guerrilla revolucionaria extendieron y consolidaron su alcance geográfico e influencia política debido a la inhabilidad de los sucesivos gobiernos para atacar los problemas en el campo. Los narcotraficantes entraron también en escena y extendieron su alcance, en especial en las zonas de colonización, confome al desplazamiento de los cultivos de coca de Perú y Bolivia a Colombia. Tanto terratenientes como campesinos están involucrados en el cultivo de coca, lo que mitiga el conflicto de clases porque ambos se oponen a los intentos del Estado por erradicarlo y combatir a los intermediarios. El gobierno de E.E.U.U. ha ejercido una influencia cada vez mayor en la política de Colombia con respecto al problema de la coca. La propaganda del gobierno ha desvirtuado las demandas sociales legítimas de la población rural, alegando que se trata de un problema de narcotráfico, para así justificar las medidas represivas. Se estima que cerca de 35,000 personas fueron asesinadas y que unos 800,000 campesinos han sido desplazados de sus poblados y tierras durante la década pasada como resultado de los conflictos y la violencia ( The Economist, núm. 8143, 1999, p. 68). Se calcula que los narcotraficantes han adquirido entre el $20 \%$ y $40 \%$ de la tierra agrícola del país. La población rural sufre a manos del Estado, los paramilitares, la guerrilla y los narcotraficantes. Es importante resaltar que una de las deman- 
das centrales de los guerrilleros rebeldes es la reforma agraria.

En resumen, el análisis del caso colombiano revela, en palabras de Meertens (1997, p. 249), que:

A lo largo del siglo XX las luchas campesinas por la tierra y las respuestas terratenientes, en tanto manifestaciones de lucha de clases en el campo, se han visto desdibujadas no sólo por la variedad de las estructuras agrarias regionales, sino también por su permanente inserción en conflictos políticos de otra indole, cuyas divisiones atraviesan las líneas de clase. Tal vez ha sido ésta la característica más importante de la historia rural colombiana.

Esta afirmación es particularmente válida si se recuerda que los narcotraficantes han permeado el sistema político de Colombia hasta el más alto nivel y por tanto se han convertido en actores muy importante en los conflictos políticos del país.

\section{El movimiento de los campesinos sin tierra en Brasil}

El principal protagonista en el campo de Brasil durante las últimas décadas ha sido el Movimiento de Trabajadores Rurales sin Tierra (MST) que agrupa a unos 500,000 afiliados, lo cual lo convierte en el movimiento campesino más importante de América del Sur. Ha sido la punta de lanza de más de mil invasiones de tierras con la demanda de expropiarlas ya que por lo general son ociosas y pertenecen a latifundistas. No sorprenden estas acciones puesto que la distribución desigualdad de la tierra es un problema particularmente agudo en Brasil, donde sólo 4\% de los propietarios controlan 79\% de la tierra cultivable del país (Veltmeyer et al., 1997). Más aún, se calcula que hay alrededor de 2.5 millones de campesinos sin tierras en Brasil. Éstos también empezaron a ejercer presión sobre el gobierno 
mediante acciones directas que incluían bloqueos de carreteras y plantones en las oficinas locales del Instituto de la Reforma Agraria (INCRA). La lucha por la tierra ha originado muchas muertes, debido a que los fazendeiros y sus pistoleros han actuado impunemente. Muchos ocupantes también murieron o resultaron heridos en enfrentamientos con la policía militar.

El liderazgo del MST reconoce la necesidad de hacer alianzas con otras organizaciones sociales y políticas a fin de lograr el apoyo público a sus objetivos. Por ello ha desarrollado vínculos con el Partido de los Trabajadores (PT) que, aunque llenas de tensión, ya forman parte de un proyecto más amplio de transformación social y política. El MST es quizás el movimiento social más dinámico, creativo e influyente del Brasil de las últimas décadas. Con excepción de Argentina, Brasil ha sido el único país en América Latina que no había llevado a cabo ninguna reforma agraria importante. Esta demora puede explicarse por el poder político de los hacendados, quienes tenían la capacidad de bloquear cualquier intento de reforma agraria, y por la decisión del Estado de abrir la región del Amazonas a la colonización, que alivió un poco la presión por la tierra de la masa empobrecida de los campesinos y trabajadores rurales sin tierra. Esta colonización de la frontera proporcionaba una válvula de escape temporal al liberar las tensiones sociales en el campo conforme abrían posibilidades de migración y de mejorar la situación de algunos trabajadores del campo. Sin embargo, la colonización misma fue un proceso violento. Gran parte de la violencia en la región fronteriza fue resultado de acciones de las personas con poder que reclamaban como de su propiedad la tierra colonizada por campesinos pioneros (posseiros) y que con frecuencia fueron expulsados por la fuerza. Debido a la falta de infraestructura institucional en la región fronteriza, se hizo frecuente el uso de la violencia para resolver los conflictos, en vez de acudir a mecanismos legales y administrativos del Estado. La violencia se utilizó también como medio de control social por parte de los grupos dominantes y para ejercer su dominio sobre los colo- 
nos. Así, al aligerar la potencial intensificación del conflicto en la región de origen de los migrantes, esta colonización generaba nuevos conflictos y violencia en la región fronteriza.

En síntesis, la violencia generalizada en el Brasil rural es una expresión de la lucha por la tierra y la supervivencia de los pobres del campo. La reforma agraria sigue siendo un asunto crucial para atacar la pobreza y la violencia rural. Cuando Cardoso asumió la presidencia del país en 1994 las acciones del MST han logrado acelerar el proceso de reforma agraria. Hasta la fecha se han asentado a más de 300,000 familias campesinas. Aunque ello es una avance significativo comparado con el pasado, los beneficiarios son todavía tan sólo una fracción de los trabadores rurales sin tierra y el problema de la tierra está lejos de haberse resuelto.

\section{La rebelión de Chiapas en México}

A primera vista, la rebelión campesina en Chiapas encabezada por el Ejército Zapatista de Liberación Nacional (EZLN), que apareció en la escena política el 1 de enero de 1994, no apoyaría la proposición de este trabajo Después de todo, México vivió la primera y más importante revolución agraria y campesina en la América Latina postcolonial. La consecuencia de ello es que la reforma agraria más antigua, y una de las más amplias que se haya puesto en marcha en el continente, se llevó a cabo en México. De hecho, desde la Revolución, el país ha disfrutado de una relativa estabilidad política, aunque la violencia continúe presente pero generalmente en un nivel inferior a otros países de América Latina. Sin embargo, reflexionando más detenidamente la rebelión de Chiapas se puede interpretar como avalando la proposición que se presenta en este ensayo debido a las particularidades de dicha región. Sin duda que este trascendente movimiento tiene múltiples causas, que es un movimiento en desarrollo y sus ramificaciones van más allá del problema de la tierra. Chiapas tiene frontera con Guatemala, es el estado 
Sociologias, Porto Alegre, ano 5, no 10, jul/dez 2003, p. 220-248

más sureño de México, de gran población indígena y pobreza extrema. La reforma agraria se introdujo tardíamente y con menor intensidad que en otras regiones. Pero la rebelión de Chiapas no es solamente la lucha por la tierra, sino también por un proceso democratizador y de desarrollo inclusivo. Como lo establece Burbach (1994, p. 113),

no se trata de una revuelta de la gente indigena con el solo propósito de recobrar sus tierras y expulsar a los ricos que los han explotado. Ni tampoco, como lo demostraron los dos mil indígenas levantados en armas el 1 de enero, se trata de un movimiento «foquista» en que unos pocos guerrilleros incitan al resto de la población a apoyarlos. Y no se trata de una lucha parecida a la de Sendero Luminoso en la cual el ejército de indigenas o campesinos intenta destruir todo lo que se atraviese en su camino para apoderarse del control absoluto del Estado [...] Lo que distingue al EZLN de sus predecesores es que no está interesado en conquistar el poder en la ciudad México ni clama por un estado socialista. Su objetivo es desatar un amplio movimiento de base de la sociedad civil, en Chiapas y en el resto de México, que transformase el país desde abajo.

Más aún, la de Chiapas es una rebelión contra el neoliberalismo y la globalización, contra el Tratado de Libre de Comercio con América del Norte (TLCAN) y, en especial, contra la reforma al artículo 27 de la Constitución - artículo que representa uno de los principales logros del movimiento agrario de 1910 a 1917 -, la cual puso fin a la reforma agraria en 1992. La cancelación al reparto de tierras y la amenaza a la supervivencia de los campesinos por la importación de productos agrícolas baratos, especialmente maíz, proveniente de E.E.U.U. después del convenio del TLCAN, 
son algunas de las razones principales de esta rebelión. El cultivo campesino de maíz se encuentra en peligro por las políticas neoliberales del gobierno en que se han retirado al sector campesino subsidios, créditos, ayuda técnica y otros servicios. El maíz es un cultivo cuya importancia para la supervivencia de los campesinos no es únicamente económica, sino también cultural y simbólica. En resumen, la rebelión en Chiapas se debe a los efectos de la modernización agrícola de México que excluye al campesinado, y al temor de que la integración de México al TLCAN lo margine aún más. Los productores campesinos en México no pueden competir con los grandes productores mecanizados de maíz y cereales de América del Norte, que además reciben sustanciales subsidios gubernamentales, a menos que se adopten medidas especiales de protección y desarrollo en su favor. De hecho, la rebelión de Chiapas ha llegado a ser el símbolo del nuevo carácter de los movimientos sociales del campo en América Latina, que están en el frente de lucha contra el neoliberalismo.

\section{Guerra y paz en América Central}

El problema de la tierra no era solamente un factor importante en la historia de la violencia en América Central sino que también jugó un papel central en los convenios de paz en América Central mediante los cuales Nicaragua, Guatemala y El Salvador están tratando de encontrar una solución a la guerra civil que ha asolado sus países. Es conveniente valorar la magnitud de esas guerras civiles. Según algunas cifras, durante esos conflictos han muerto cerca de 300,000 personas en Guatemala, El Salvador y Nicaragua, y dos millones (casi $13 \%$ de la población total) fueron desplazadas, ya fuera hacia el extranjero o hacia lugares más seguros dentro del mismo país. La mayoría de estos actos violentos fueron cometidos por las fuerzas gubernamentales $y$, en menor medida, por las fuerzas paramilitares o escuadrones de la muerte, y por grupos guerrilleros (Pearce, 1998, p. 590-91). El presidente de Costa 
Rica, Oscar Arias, tomó la iniciativa en 1986 de buscar una solución política a la guerra civil en esos países. Sus esfuerzos dieron como resultado el convenio de Esquipulas II de 1987 que allanó el camino para terminar con las guerras civiles. Sin embargo, Nicaragua no firmó los convenios de paz sino hasta 1990, El Salvador en 1992 y Guatemala en 1996.

En Nicaragua la tierra estaba altamente concentrada y el dictador Anastasio Somoza era el latifundista más grande del país. La Revolución sandinista arrojó a Somoza del poder en 1979 y estructuró una reforma agraria radical que expropió casi la mitad de la tierra agrícola del país y benefició a más de una tercera parte del campesinado. Los latifundios expropiados se organizaron en granjas estatales, en cooperativas de producción en ciertos casos, y sólo una pequeña parte de las expropiaciones se entregó directamente a los beneficiarios como granjas familiares privadas. El gobierno sandinista temía que con la subdivisión de los grandes latifundios se perdieran las economías de escala y, sobre todo, peligraran los ingresos del país por exportaciones, porque los campesinos beneficiarios podían cambiar sus cultivos de exportación por los de subsistencia. La política socialista y factores ideológicos apoyaban también el énfasis al colectivismo. Los terratenientes y otras fuerzas sociales opuestas a la revolución comenzaron a organizarse en una rebelión armada para derrocar al gobierno. Recibieron gran apoyo de Estados Unidos durante la administración de Reagan como parte de la guerra fría para combatir cualquier revolución socialista. Los grupos contrarrevolucionarios (denominados «los contras») se aprovecharon del disgusto de muchos campesinos por la política agraria del gobierno sandinista y por el carácter colectivista del sector reformado. El conflicto armado entre los «contras» y el gobierno dañaron severamente la economía y la producción agrícolas. Los campesinos, sin embargo, pudieron presionar con éxito al gobierno sandinista para que adoptara una reforma agraria menos estatista. Después de 1984, algunas granjas estatales fueron transferidas directamente a los campesinos benefi- 
ciarios, ya fuera mediante propiedad cooperativa o individual. Este cambio de política fue provocado también por la necesidad de reducir la influencia de los "contras" en el campesinado y estimular la producción de alimentos. A partir de este cambio de política, la tierra expropiada y redistribuida entre los campesinos beneficiarios como propiedad individual, aumentó de 8\% entre 1981 y 1984 a 24\% entre 1985 y 1988. Los campesinos beneficiarios obtuvieron asimismo un acceso más favorable a los escasos insumos, modificándose el trato ventajoso otorgado con anterioridad a las granjas estatales. Sin embargo, la guerra civil y el deterioro económico resultante en el país significó que los campesinos enfrentaran una difícil situación. La reforma agraria sandinista también originó que los campesinos hicieran un esfuerzo importante para organizarse. El gobierno ayudó a establecer la Unión Nacional de Agricultores y Ganaderos (UNAG) en 1981, y para 1987 se había unido a ella una quinta parte de los trabajadores agrícolas. La UNAG logró con el tiempo arrebatarle al Estado un grado más elevado de autonomía y se transformó en la organización campesina más importante del país.

Los sandinistas no pudieron conseguir el apoyo de la mayoría de los campesinos, a pesar del cambio en sus políticas, como lo evidenciaron los resultados de las elecciones de 1990 en las que sólo 36.3\% del voto rural del país fue para el FSLN, el partido del gobierno, comparado con $44.2 \%$ del voto urbano (Horton, 1998, p. 261). Es posible que el FSLN hubiera alcanzado un resultado electoral más favorable en las zonas rurales si desde el inicio de la reforma agraria hubiera repartido a los campesinos beneficiarios los derechos de propiedad individual; de esa manera, es posible que menos campesinos habrían apoyado a los "contras". Como escribe Horton (1998, p. xii):

La gran mayoría de los comandantes y combatientes contras eran campesinos [...] Es posible que unos 30,000 nicaragüenses se hayan enrolado en algún momento en las fuerzas anti-gubernamentales, haciendo de los contras una de las movilizaciones armadas de campesinos más grande en la historia contemporánea de América Latina. 
La guerra civil en Nicaragua de los años ochenta tuvo costos humanos y económicos devastadores. "Durante la guerra murieron 30865 nicaragüenses de una población aproximada de 3.5 millones. Esta guerra desplazó a más de 350000 personas, en especial de las áreas rurales" (ibid, p. xi). Esto obligó al gobierno sandinista a firmar los convenios de paz anteriormente mencionados. Los convenios llamaban a terminar con la ayuda externa a los "contras" a cambio de elecciones democráticas en Nicaragua. Ello condujo en principio al cese temporal del fuego y, después de la derrota del FSLN en las elecciones de 1990, al cese permanente del fuego y la desmovilización de los "contras".

Con la victoria de Violeta Chamorro en las elecciones de 1990, el nuevo gobierno cambió la política agraria. El reparto de tierras para combatientes de ambos lados en la guerra civil fue un elemento central de pacificación. Sin embargo, abrió también nuevos conflictos y nueva violencia. Ello surgió de la situación caótica que prevalecía en el campo por las múltiples solicitudes de tierra. Los latifundistas exigían la devolución de su tierra expropiada; los beneficiarios querían subdividir las granjas agrícolas estatales y colectivas para obtener títulos de propiedad privada, e impedir así que los latifundistas y los "contras" adquirieran tierras del sector reformado; los "contras" exigían una parcela de tierra a cambio de dejar las armas, y los campesinos sin tierra que habían sido ignorados por el gobierno sandinista exigían también un pedazo de tierra. No fue ninguna sorpresa que surgiera esporádicamente la violencia en el campo, en especial si se considera que "en 1995, 47\% del total de la tierra cultivable del país no contaba con un título legal, y que los antiguos propietarios habían registrado 7,185 demandas correspondientes a 25\% del total de la tierra cultivable" (ibid., p. 279). Resulta paradójico que a pesar de que los "contras" ayudaron a la victoria de las fuerzas antisandinistas, algunos de ellos tomaron de nuevo las armas para luchar por un pedazo de tierra, ya que el gobierno o no había respondido a sus demandas o lo había hecho muy lentamente. 
Los ex contras, de nuevo levantados en armas, son conocidos como los "recontras". Piensan que sólo mediante la violencia pueden lograr que el gobierno preste atención a sus exigencias de tierra.

Las extremas desigualdades y las condiciones de explotación en el campo de El Salvador fueron la causa de la sublevación campesina de 1932, brutalmente sofocada por las fuerzas armadas y los terratenientes. Según algunos cálculos, murieron entre 30,000 y 40,000 personas, aunque otros piensan que la cifra fue de 20,000, de una población de solamente un millón en ese momento. Es por ello por lo que esta masacre es conocida como "La Matanza". Los indios en particular fueron el blanco de tal carnicería. La masacre aseguró que continuara la dominación de la oligarquía terrateniente en muchas décadas por venir. Sólo al final de los años setenta los conflictos resurgieron cuando los campesinos sintieron que sus niveles de vida decaían peligrosamente, con lo cual el país estuvo a punto de sumergirse en una guerra civil. En 1980 el gobierno decretó la reforma agraria para enfrentar la creciente ola de conflictos. Pero la reforma agraria pronto encontró la poderosa oposición de los terratenientes que limitaron su aplicación efectiva y desencadenaron un período de guerra civil que duró hasta 1992. El gobierno esperaba que la reforma construyera las bases para una estabilidad social y una paz duradera, pero la oligarquía latifundista movilizó a sus aliados en las fuerzas armadas y de seguridad para que no se consumara el proceso de expropiación. La alianza entre la élite agroexportadora y los militares resultó en una brutal represión de campesinos, con frecuencia indiscriminada, la cual condujo a muchos de ellos a la resistencia armada. No obstante, la reforma agraria de 1980 en El Salvador se las arregló para distribuir más de una quinta parte de la tierra a $20 \%$ de los trabajadores rurales. Sin embargo, esta reforma no pudo ofrecer nada a una gran masa de campesinos sin tierra. Se organizaron cooperativas de producción en la mayoría de las granjas expropiadas, pero cerca de una quinta parte de su área fue cultivada de forma individual. Sólo una 
pequeña proporción de las granjas expropiadas fue subdividida y repartida individualmente a los beneficiarios como granjas privadas de familias campesinas.

Los doce años de guerra civil cobraron entre 200,000 y 300,000 vidas de las cuales una aplastante mayoría fueron víctimas de las fuerzas armadas y de los escuadrones de la muerte. El saldo de muertes equivale a 1.5\% de la población, además de que la guerra desplazó de sus hogares a otro 30\% (Brockett, 1994: 175). Sin embargo, la reforma agraria debilitó el poder de los terratenientes y abrió las puertas a las negociaciones de paz . La firma del convenio de paz el 16 de enero de 1992 dio formalmente por terminada la guerra civil, la guerrilla participó en el proceso de pacificación y se convirtió en un partido político. Este proceso de institucionalización se consideró una forma de reducir los conflictos o, por lo menos, de encontrar mecanismos de paz para resolverlos y así reducir la violencia. Pero la violencia esporádica continúa en El Salvador, y la policía y los paramilitares participan en ella. Es más, la reforma agraria de 1980 sigue inconclusa porque nunca se puso en marcha la segunda etapa. Hasta existe la posibilidad de que algunos de los beneficiarios pierdan su tierra porque no tienen capacidad para pagar la deuda adquirida con la reforma agraria. Además, la continua expansión de los cultivos de exportación origina nuevos desplazamientos de campesinos, conflictos y violencia. Sin ignorar las dificultades, subscribo la conclusión de Pearce (1986, p. 303) de que "sólo una reforma agraria llevada a cabo dentro de un amplio proceso de transformación social de carácter radical puede allanar el camino a una paz duradera y al desarrollo de El Salvador".

\section{Algunas reflexiones comparativas}

A continuación enlazaré el análisis de los estudios de caso dentro de una perspectiva comparativa. Las reformas agrarias no siempre demostraron 
ser la panacea anticipada en América Latina porque los gobiernos no pudieron cumplir su promesa de repartir tantas tierras como se esperaba, ni otorgar suficiente apoyo económico y técnico al sector reformado. Incluso las reformas agrarias ocasionaron a menudo violencia por la frustración del campesinado en la lentitud, la perspectiva limitada y la estructuración de arriba-abajo del programa de reforma. Pero cuando algunos gobiernos empezaron a repartir más tierras, los latifundistas se las ingeniaron para bloquear la reforma agraria y, en algunas instancias, tuvieron la capacidad de derrocar al gobierno y adquirir parte de sus tierras expropiadas, si no todas, utilizando a menudo medios violentos, ya sea directamente con pistoleros contratados, organizaciones paramilitares o apoyándose en el poder represivo del Estado. Así, el problema de la tierra ha demostrado ser un tema central de los muchos conflictos y de la violencia en el campo; por tanto, es necesario resolverlo si los gobiernos desean alcanzar algún grado de estabilidad social y política en el largo plazo, aun cuando en una primera instancia pueda generar de nuevo la violencia. Los gobiernos deben abordar el problema de la tierra de manera frontal. Por ejemplo, los países que bloquearon las reformas agrarias o que llevaron a cabo una reforma agraria muy limitada experimentaron actos violentos posteriores, como Colombia, El Salvador, Guatemala y Brasil. En Brasil, a pesar de las crecientes exigencias de los campesinos pobres por un pedazo de tierra y las movilizaciones del MST, sólo se ha llevado a cabo hasta ahora un reparto menor. Los hacendados han podido bloquear todo tipo de reforma agraria importante en Brasil debido a las peculiaridades de su sistema político federal, en el cual las regiones rurales están sobrerrepresentadas en el parlamento. Ello ha otorgado gran influencia a los hacendados en el sistema político nacional, porque controlan gran parte de los estados rurales. Las movilizaciones campesinas han chocado contra la violencia de los terratenientes y la represión estatal. En otros países, la falta de avance en la reforma agraria ha originado el nacimiento de movimientos guerrilleros que han movilizado 
a los pobres del campo. El Estado respondió con acciones de contrainsurgencia con el apoyo del gobierno de Estados Unidos durante el periodo de la guerra fría, para combatir una amenaza subversiva, real o imaginaria, de origen comunista. Estas acciones de contrainsurgencia han sido las responsables de la mayoría de las muertes violentas y los desplazamientos masivos de la población rural en la región de América Central. La batalla de la contrainsurgencia en el período posterior a la guerra fría adquirió una nueva dimensión, como en Colombia, donde las operaciones represivas contra el campesinado se iniciaron bajo el pretexto de, o asociadas con, la guerra contra los «narcos» y la erradicación forzosa del cultivo de coca mediante operaciones militares.

Los países que han llevado a cabo reformas agrarias radicales, o amenazado con hacerlo, como El Salvador, provocaron la ira de los terratenientes, por lo que tampoco se han librado de la violencia. Una reforma agraria de carácter popular originó en Guatemala el derrocamiento de Arbenz en 1954 y una violenta contrarreforma en la cual gran parte de la tierra expropiada fue devuelta a los antiguos terratenientes. Esto sólo agravó el problema en Guatemala y lo pospuso por una década o dos, originando más violencia. La reforma agraria de 1980 en El Salvador ocasionó doce años de guerra civil en la cual los campesinos fueron las principales víctimas de la violencia. Se ha repartido algo de tierra, pero los latifundistas han bloqueado las fases subsecuentes de la reforma. De modo que el problema de la tierra en El Salvador aún está por resolverse y continúa siendo una fuente potencial de conflictos y violencia. En Chile, la reforma agraria masiva, pero sobre todo la «vía chilena al socialismo» de Allende, fue uno de los elementos clave en el golpe militar y de la consecuente violencia contrarrevolucionaria. No obstante, una proporción significativa de la tierra expropiada fue transferida a algunos de los beneficiarios de la reforma agraria como granjas familiares individuales. Desde la transición a la democracia en Chile en 1990, han surgido pocos conflictos violentos 
debido a la severidad de la represión anterior por parte del gobierno autoritario, pero también al proceso de parcelización que pudo satisfacer algunas de las demandas de los campesinos, aunque sólo las de una minoría. Los conflictos en años recientes han resurgido en la región indígena del sur reclamando más tierra y otros derechos. Ello se debe en parte a la dictadura militar durante la cual parte de la tierra expropiada a los latifundistas durante el gobierno de Allende y transferida a las comunidades indígenas fue devuelta a sus antiguos dueños o vendida a grandes plantaciones forestales.

México es tal vez el único caso en América Latina donde la reforma agraria alcanzó objetivos políticos de importancia desde el punto de vista de los intereses de una nueva clase dominante. Durante siete décadas o más, la reforma agraria y la habilidad del Estado mexicano para incorporar, cooptar y reprimir simultáneamente al campesinado aseguró el régimen de un solo partido y una relativa estabilidad política. Debe tenerse en mente, sin embargo, que un factor importante en el conformismo de los campesinos ha sido la represión violenta de los movimientos campesinos independientes. La rebelión neozapatista en Chiapas astilló en 1990 esta relativa estabilidad y, como se analizó con anterioridad, esa región era el eslabón más débil en la reforma agraria de México.

La reforma agraria en Perú abrió primero las puertas a una violencia ulterior. Pero con la «reforma de la reforma agraria», en la cual la tierra del sector reformado fue parcelada y/o redistribuida a comunidades indígenas, y la derrota de Sendero Luminoso, la posibilidad de lograr una mayor estabilidad social en el campo y una sociedad rural menos violenta ha mejorado notablemente. Debe recordarse también que las primeras experiencias de la reforma agraria en Perú fueron muy esperanzadoras. La reforma agraria del presidente Belaúnde Terry en el Valle de La Convención a mediados de los años sesenta logró pacificar y tamizar lo que una vez fue un movimiento campesino de insurrección. Así, antiguos arrendatarios de tipo servil adquirieron sus títulos de propiedad privada para convertirse en 
granjeros familiares capitalizados y unirse al rango de pequeña burguesía. La reforma agraria posterior, la del general Velasco Alvarado, generó diversas expectativas que no pudieron ser cumplidas y por lo mismo originó más violencia. En particular, la exclusión de muchas comunidades de campesinos indígenas del reparto de tierras hizo aparecer nuevos conflictos y violencia. Esta grieta en la reforma agraria de Perú fue explotada sin piedad por Sendero para abrir uno de los capítulos más violentos en la historia de Perú, pero que culminó con su final derrota.

En Nicaragua, a pesar de la popularidad inicial de la revolución, el carácter estatista de la reforma agraria alienó a muchos campesinos. Gran parte de la violencia fue originada por la guerra que libraron los "contras" con el gobierno sandinista, apoyados por los latifundistas expropiados y el gobierno de Estados Unidos. Los contras pudieron reclutar a muchos de los campesinos descontentos con la reforma agraria. A pesar de que la contrarreforma agraria de los gobiernos posteriores al sandinismo ha creado nuevas fuentes de conflictos y violencia, se espera que la subdivisión de las granjas agrícolas estatales y cooperativas en granjas familiares, y su reparto entre algunos de los antiguos beneficiarios y los contras, logre la pacificación en el campo. Mientras más elevado sea el número de campesinos sin tierra que logre asentarse, mayores serán las posibilidades de reducir la violencia. Hasta ahora, aún es incierta tal situación porque muchos terratenientes han podido reclamar parte de su tierra expropiada, si es que no toda, para dejar así menos tierra para ser repartida.

En Colombia se presenta un cuadro más problemático, por sus marcadas variantes regionales y su turbulenta historia, que hacen más difíciles las generalizaciones, aunque hasta cierto punto coincide con las propuestas sugeridas en este ensayo. Por ejemplo, gobiernos sucesivos intentaron apaciguar las áreas que experimentaban los conflictos rurales más intensos con reformas agrarias mínimas y localizadas. La Ley de Tierras de 1936 fue diseñada para reducir los conflictos rurales y la violencia al repartir algunas tierras federales a colonos e invasores. Los gobiernos 
intentaron frenar también el potencial revolucionario y la autonomía de los trabajadores rurales apoyando los programas de parcelización de haciendas, que experimentaban conflictos laborales importantes sobre todo en las regiones cafetaleras. Los trabajadores rurales, al convertirse en pequeños productores de café, fueron arrastrados al tejido del clientelismo de los partidos burgueses y del Estado en la competencia por créditos, subsidios y otros servicios. La particularidad del caso colombiano muestra la habilidad de los terratenientes - que pertenecen a facciones políticas contendientes de la clase dominante para movilizar a sus respectivos grupos de campesinos mediante una variedad de relaciones clientelísticas en aras de sus intereses, personales o partidistas. Con ello, la violencia rural adquirió características de tipo feudal durante el periodo de «La Violencia», además de impedir la unidad del movimiento campesino. Los conflictos rurales, con el surgimiento de poderosos movimientos guerrilleros, adquirieron un cierto carácter clasista en las últimas dos décadas. Pero la enorme influencia de la mafia de los «narcos» en casi todos los aspectos de la vida de Colombia ha distorsionado dicha situación e introduce nuevas complejidades. En resumen, la violencia en Colombia ha sido un proceso de múltiples facetas cuyas causas y enfoques han ido cambiando y evolucionando con el tiempo. No obstante, la violencia en el campo ha sido la expresión generalizada de una lucha constante por la tierra.

La importancia del tema de la tierra se ha manifestado también en los Acuerdos de Paz en América Central, en los cuales el reparto de tierras era un ingrediente significativo para lograr la desmovilización de las facciones combatientes y alcanzar un cierto nivel de estabilidad política. Es importante observar también que Argentina y Costa Rica, los dos países con relativamente menos violencia rural en la región, cuentan con una estructura agraria más igualitaria y una clase media rural más amplia, comparados con los demás países de América Latina. En esos países, las luchas del campesinado no se centran en una reforma agraria, sino en mejores precios para sus productos agrícolas, acceso a créditos más baratos, protección contra la competencia extranjera, rentas bajas para los arrendatarios, aumento de salarios y mejores condiciones de trabajo. 


\section{Conclusiones}

En este artículo he expuesto que la gran desigualdad del sistema agrario, las consecuentes relaciones de explotación y dominación, y los procesos de modernización excluyentes, son factores importantes, y en algunos casos los más prominentes, para explicar los conflictos y la violencia en la América Latina rural. Sin embargo, no es posible dar una sola y simple respuesta respecto de las causas de la violencia rural, su persistencia o resurgimiento, y de las posibles formas de enfrentarla, regularla, por no decir, resolverla. Aunque es posible encontrar algunos rasgos comunes, existen también variantes derivadas de las peculiaridades estructurales y coyunturales de cada país, así como de las diversas acciones de los terratenientes, campesinos, el Estado y otros actores importantes tales como grupos urbanos, partidos políticos y el gobierno de E.E.U.U.

En este ensayo me he empeñado en analizar especialmente las relaciones entre la estructura agraria, la reforma agraria y la violencia en el campo a fin de examinar la propuesta de que una de las causas más importantes de los conflictos y la violencia entre latifundistas, campesinos y otros actores sociales tiene su raíz en un sistema agrario altamente inequitativo. Esta propuesta sugiere que los países que tienen un sistema agrario más igualitario y un proceso de desarrollo más incluyente a su vez tienen una sociedad rural menos violenta. El Estado juega un papel central en el surgimiento, desarrollo y solución de los conflictos y violencia rurales y, por lo mismo, quienes diseñan las políticas públicas tienen especial responsabilidad en examinar las lecciones que se puedan derivar de experiencias previas tales como las discutidas en este ensayo. Si bien la reforma agraria puede ser una precondición para una sociedad rural más integrada y estable, la reducción de la violencia rural depende, en última instancia, de la institucionalización exitosa de conflictos mediante la cual los grupos sociales agraviados pueden negociar sus demandas por canales legales y políticos, así como del desarrollo y solidez de las instituciones y 
prácticas democráticas. En resumen, la solución al problema de la tierra y la violencia rural es parte esencial del proceso de democratización de la sociedad en su conjunto.

\section{Referencias}

BLUM, V. Senderos enredados: los desplazamientos y el proceso de retorno en Ayacucho. En: K. Bodemer, S. Kurtenbach y K. Meschkat (Eds.). Violencia y Regulación de Conflictos en América Latina. Nueva Sociedad: Caracas, 2001, p. 341-359.

BROCKETT, C. D. El Salvador: the long journey from violence to reconciliation. In: Latin American Research Review, v. 29 (3), 1994, p. 174-187.

BURBACH, R.. Roots of the postmodern rebellion in Chiapas. In: New Left Review, n. 205,1994 , p. 113-124.

DEGREGORI, C. I., Campesinado andino y violencia: balance de una década de estudios. En: C. I. Degregori, J. Escobal y B. Marticorena (comps.). Perú: el Problema Agrario en Debate, SEPIA IV, Lima, 1992, p. 413-439.

HORTON, L. Peasants in Arms: War and Peace in the Mountains of Nicaragua, 1979-1994. Ohio: U. Press., 1998.

MEERTENS, D. Tierra, Violencia y Género: Hombres y Mujeres en la Historia Rural de Colombia 1930-1990. Nijmegen: Derde Wereld Centrum Ontwikkelingsstudies, 1997.

OQUIST, P. Violence, Conflict, and Politics in Colombia. Nueva York: Academic Press, 1980.

PEARCE, J. Promised Land: Peasant Rebellion in Chalatenango, El Salvador. Londres: Latin America Bureau (LAB), 1986.

PEARCE, J. From civil war to 'civil society': has the end of the Cold War brought peace to Central America?. In: International Affairs, v. 74, n. 3, 1998, p. 587-615.

VeLTMEYER, H., J. Petras y S. Vieux. Neoliberalism and Class Conflict in Latin America. Macmillan: Londres, 1997. 
Sociologias, Porto Alegre, ano 5, no 10, jul/dez 2003, p. 220-248

WOLF, E. R.. Die Phasen des ländlichen Protests in Lateinamerika. En: E. Feder (Comp.), Gewalt und Ausbeutung: Lateinamerikas Landwirtschaft. Hamburgo: Hoffmann und Campe, 1973, p. 273-286.

\section{Resumen}

La violencia rural ha adquirido niveles dramáticos en muchos países de América Latina durante las últimas décadas. Es por ello crucial analizar los orígenes de la violencia rural para buscar formas de solucionar los problemas que causan dicha violencia. El propósito de este ensayo es explorar las relaciones entre la estructura agraria, la reforma agraria y la violencia rural en América Latina. Sus interrelaciones se examinan desde una perspectiva histórica en la cual se privilegian los procesos globales de transformación. Factores tales como el régimen político, los mercados, la tecnología, los cultivos (por ejemplo, la coca) y las acciones del Estado tienen una presencia importante en los varios tipos de conflicto y violencia en el campo. Sin embargo, el grado de influencia de estos factores varía en buena medida según las características de la estructura agraria y las relaciones sociales existentes. Se examina en particular la influencia de las reformas agrarias y/o las demandas de los campesinos por una reforma agraria en los conflictos y la violencia rural tomando en consideración los casos de Chile, Perú, Colombia, Brasil, México y algunos países de América Central. En las conclusiones de este trabajo se presentan algunos discernimientos comparativos, si bien preliminares. Comprendo que éstos todavía deben desarrollarse más, pero espero que puedan constituir un punto de partida para otros análisis comparativos de mayor extensión. Los estudios sobre conflictos rurales y violencia se han enfocado hasta hoy principalmente en un país particular. Los estudios comparativos, en mi opinión, pueden aportar un marco analítico más amplio y el contexto comparativo puede abrir nuevas posibilidades para una mejor comprensión de las causas y consecuencias de la violencia rural en los países de América Latina.

Palabras-clave: estrutura agraria, violencia rural, América Latina. 